\title{
DESIGN AND PREPARATION OF SAMPLES FOR THE INTERNATIONAL COLLABORATIVE STUDY
}

\author{
D D HARKNESS*, G T COOK**, B F MILLER*, E M SCOTT ${ }^{\dagger}$ \\ and M S BAXTER**
}

ABSTRACT. Sample materials issued to participants in the interlaboratory calibration exercise are defined and in context of their intended interpretational significance. Preparation of the benzene and calcium carbonate standards as issued for stage 1 is described in detail; likewise, the source and pretreatment/extraction of the environmental samples dispatched for stages 2 and 3 .

\section{INTRODUCTION}

Although conscious of the need to maintain a precise definition of the conventional radiocarbon time scale (Godwin, 1962; Stuiver \& Polach, 1977; Stuiver, 1983; Mook, 1985), the international ${ }^{14} \mathrm{C}$ dating community has been collectively less concerned with the need for formal interlaboratory calibration programs as recognized in other areas of analytical science, eg, in the related field of natural ${ }^{3} \mathrm{H}$ measurement (Taylor, 1978). In general, a system of sporadic and ad hoc exchange of samples among individual or small groups of laboratories has prevailed, with the implication that this was adequate for both internal and user confidence. With the significant expansion in applied ${ }^{14} \mathrm{C}$ dating during recent years, it is now doubtful that this approach is adequate. Where such questions arise, they inevitably focus on the comparability of conventional age reports issued by different laboratories.

Following from the consensus expressed during the 12th International Radiocarbon Conference in favor of a new and comprehensive intercalibration study, the aims and proposed design for this exercise were set out in Scott et al (1986). The development of this strategy, with its 3-stage structure, was heavily influenced by the outcome of previous interlaboratory comparisons (Clark, 1975; Pardi \& Marcus, 1977; Otlet et al, 1980; ISG, 1982, 1983). The major purpose was to give participating laboratories the opportunity for direct peer assessment of the experimental accuracy and precision achieved for the component stages in their overall dating performance. Furthermore, this type of data set was seen as fundamental to the objective statistical analysis necessary for resolving the all-important questions of user confidence.

\section{AIMS IN SAMPLE COLLECTION}

It was evident that the preparation and/or procurement of a suite of appropriate samples would be crucial to the success of the collaborative study and also to justify the time and effort of the ca 60 laboratories willing to participate. We thought that the samples should be as representative as

\footnotetext{
*Natural Environment Research Council (NERC) Radiocarbon Laboratory, Scottish Universities Research and Reactor Centre (SURRC), East Kilbride, Scotland

**Glasgow University Radiocarbon Laboratory, SURRC, East Kilbride

†Department of Statistics, Glasgow University, Scotland
} 
possible of the types of material and age range most commonly used in routine dating. Specific goals of each stage had to be acommodated, and this, in context of the different analytical procedures used for determining natural ${ }^{14} \mathrm{C}$ enrichment, ie, gas proportional (GP) counting, liquid scintillation (LS) counting and accelerator mass spectrometry (AMS). The quality and isotopic homogeneity of batch samples intended for participant groups was, of course, paramount.

\section{SAMPLE DEFINITION}

Samples issued in the study derived from batches of material which were either produced in the East Kilbride laboratories or available in the required bulk from natural sources. At each stage, participants were offered a choice of the materials most appropriate to their analytical method or general interest.

\section{Stage 1 Samples}

The goal was a direct assessment of the inter- and intralaboratory variance as determined by ${ }^{14} \mathrm{C}$ counting procedures. Two types of sample were availabe - benzene and calcium carbonate. The option of preparing a range of accurately defined ${ }^{14} \mathrm{C}$ specific activities for each of the materials was discounted after we considered the practical constraints and the unavoidable addition of uncertainty (sample preparation variance) into the resultant statistical comparison. Thus, the entire stage 1 was based on only four bulk samples, ie, two batches of each material prepared to represent ${ }^{14} \mathrm{C}$ enrichment values of ca 100 and ca $50 \%$ modern. Precise definition of the ${ }^{14} \mathrm{C}$ specific activities was not attempted before distribution since we thought it more appropriate for statistical comparison that the laboratories receive aliquots of identical ${ }^{14} \mathrm{C}$ concentration, in duplicate. The latter was effectively camouflaged by a coding system.

Benzene Production. The two bulk standards were prepared by progressive dilution with scintillation-grade benzene (Koch Light) of a ${ }^{14} \mathrm{C}$ labeled benzene standard obtained from Amersham International plc. Three dilution stages were used to arrive at an "intermediate" ${ }^{14} \mathrm{C}$-spiked standard with a theoretical specific activity of $42 \mathrm{dpm} / \mathrm{mL}$ (Table 1). This was transferred to a $2.5 \mathrm{~L}$ Winchester storage bottle and held at $8 \pm 1^{\circ} \mathrm{C}$ with periodic shaking for four days. Random samples from the solution showed a consistent ${ }^{14} \mathrm{C}$ specific activity of $40.9 \pm 0.2 \mathrm{dpm} / \mathrm{mL}$. Final dilution to produce the samples required for distribution was from this intermediate standard, 1) $480 \mathrm{~mL}$ bulked to $2 \mathrm{~L}$ and 2) $230 \mathrm{~mL}$ bulked to $2 \mathrm{~L}$. These final preparations were stored in screw-cap glass bottles and routinely shaken over a two-week period. Aliquots $(15 \mathrm{~mL})$ were dispensed with an automatic pipette into glass ampules that were immediately flame-sealed. Vials for dispatch were selected and coded at random from each batch.

The adequacy of the flame-sealed glass containment and its possible influence on benzene purity was studied before general dispatch. Four ampules were charged with unspiked scintillation-grade benzene, flamesealed and stored at $20 \pm 2^{\circ} \mathrm{C}$ for one week. The vials were then placed in a vacuum desiccator and pumped to 20 Torr to simulate possible flight cargo 


\section{TABLE 1}

Preparation sequence for ${ }^{14} \mathrm{C}$-spiked benzene samples (All dilutions were with Koch Light scintillation-grade benzene)

\section{Intermediate spike}

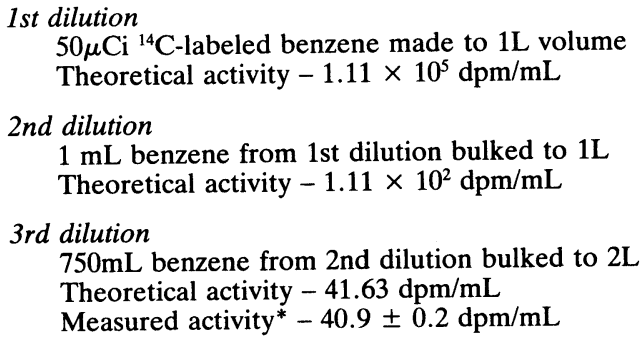

Bulk standards as distributed

Ca $100 \%$ modern benzene

$480 \mathrm{~mL}$ "intermediate spike" bulked to $2 \mathrm{~L}$

Anticipated activity $-9.82 \pm 0.05 \mathrm{dpm} / \mathrm{mL}$

Dating target $-800-1000$ yr BP

Ca $50 \%$ modern benzene

$230 \mathrm{~mL}$ "intermediate spike" bulked to $2 \mathrm{~L}$

Anticipated activity $-4.70 \pm 0.03 \mathrm{dpm} / \mathrm{mL}$

Dating target $-6700-6900$ yr BP

*Measured activity of the "intermediate spike" was determined using a Packard $2000 \mathrm{CA} / \mathrm{LL}$ counter with absolute ${ }^{14} \mathrm{C}$ detection efficiency defined by manufacturer's standards. The quoted dating target values are based on this intermediate measurement.

conditions. The glass containment proved secure. All ampules were opened and the benzene used to prepare scintillation cocktails $(10 \mathrm{~mL}+0.13 \mathrm{~g}$ butyl PBD). The spectral response to the Compton standardization source of a Packard 2000 CA/LL LS counter was monitored in direct comparison with identical cocktails prepared from a fresh stock of scintillation-grade benzene. No alteration to benzene purity was induced by the sealing procedure or containment in the glass ampules.

Carbonate Production. Our first choice was barium carbonate, precipitated directly from carbon dioxide of known specific activity. However, the shipping agent could not handle this material within his budget and so, calcium carbonate was the best alternative. This was produced by precipitation from carbon dioxide absorbed as a gas into aqueous potassium hydroxide.

$$
\begin{aligned}
& 2 \mathrm{KOH}+\mathrm{CO}_{2} \rightarrow \mathrm{K}_{2} \mathrm{CO}_{3}+\mathrm{H}_{2} \mathrm{O} \\
& \mathrm{K}_{2} \mathrm{CO}_{3}+\mathrm{CaCl}_{2} \rightarrow \mathrm{CaCO}_{3}+2 \mathrm{KCl} \\
& 2 \mathrm{KOH}+\mathrm{CO}_{2}+\mathrm{CaCl}_{2} \rightarrow \mathrm{CaCO}_{3} \downarrow+2 \mathrm{KCl}+\mathrm{H}_{2} \mathrm{O} .
\end{aligned}
$$


We obtained the required ${ }^{14} \mathrm{C}$ enrichment by using two commercially available sources of solid $\mathrm{CO}_{2}$ (dry ice), 1) produced from oil refining (British Oxygen $\mathrm{Co}$ ) and 2) a by-product from fermentation of grain (Distillers Company Ltd).

Appropriate amounts of dry ice from each source (representing $0 \%$ and ca $120 \%$ modern ${ }^{14} \mathrm{C}$ concentration) were mixed in a grinding mill. The mass of "carbon dioxide snow" was then allowed to sublime through $8 \mathrm{M}$ potassium hydroxide in a sealed collection train (Fig 1). Following absorption, the alkali solution was thoroughly mixed and a hot saturated solution of calcium chloride was added to precipitate calcium carbonate. The precipitation slurry was mixed, decanted and washed ten times with distilled water, then recovered by filtration and dried at $60^{\circ} \mathrm{C}$ in a vacuum oven. The final product was ground in a mortar, sieved, mixed and stored in screwcapped jars before dispensing.

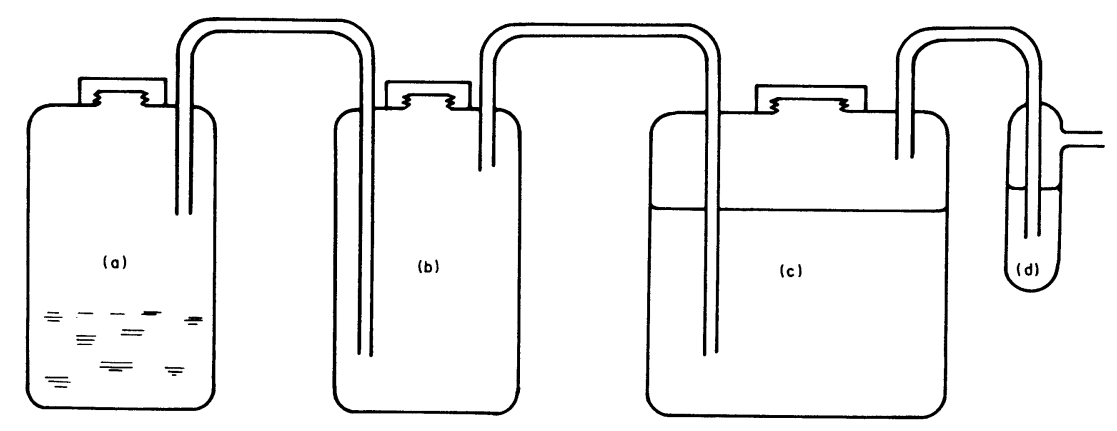

Fig 1. Carbon dioxide absorption train: (a) dry-ice snow in $50 \mathrm{~L}$ carbouy; (b) gas-diffusion volume; (c) $60 \mathrm{~L}$ $8 \mathrm{M} \mathrm{KOH}$ in $100 \mathrm{~L}$ carbouy; (d) absorption indicator trap $\left(\mathrm{Ba}(\mathrm{OH})_{2}\right.$ solution)

Sufficient carbonate (ca $2.5 \mathrm{~kg}$ ) to satisfy the total stated requirement from registered participants was prepared in a single absorption/precipitation sequence. Due to the preparation of calcium salt, the final product could possibly contain trace calcium hydroxide impurities. This would be reflected in the non-stoichiometric recovery of carbon dioxide by acid hydrolysis, which should have had no influence on the radiometric enrichment of the component carbon. Recipients were alerted that, due to its organic derivation, the stable isotope enrichment $\left(\delta^{13} \mathrm{C}\right)$ of the synthesized carbonate would be considerably lighter than that anticipated from a geological source.

\section{Stage 2 Samples}

This stage offered the opportunity to assess the contribution from routine preparation and/or synthesis methods in determining overall analytical confidence. As for stage 1, the sample options were structured to ensure the distribution of duplicates from isotopically homogeneous batches prepared from algal carbonate, peat and wood. The source of raw sample materials and pretreatment were as follows: 
Carbonate. A bulk sample of marine algae (Lithothamion) was collected from a natural coastal deposit in Argyll, Scotland. The sample was hand-sorted to remove shell fragments and then leached in dilute (0.05M) hydrochloric acid to discard the outermost $10 \%$ by weight. The residual material was washed free of acid in distilled water and dried to constant weight. The bulk sample was thoroughly mixed at various stages, during collection, before hydrolysis, during washing and after drying.

Humic Extract. Well-humified peat was collected from the basal $20 \mathrm{~cm}$ of a freshly cut exposure in central Scotland. The raw sample was air-dried and sieved through a $3 \mathrm{~mm}$ mesh to remove large root fragments, oven-dried and mixed by several passages through a grinding mill. Half of this product was retained for stage 3 distribution. The remainder was subjected to successive digestions in $2 \mathrm{M}$ potassium hydroxide and the alkali-soluble extracts were recovered by filtration and combined. The humic acid fraction was precipitated from the bulk solution by adjusting to $\mathrm{pH} 3$ with sulfuric acid. The humic slurry was separated by centrifugation, rebulked, washed several times with distilled water and oven dried at $70^{\circ} \mathrm{C}$. The resultant granules were digested in and washed with boiling distilled water and redried to constant weight. The final product (ca $2 \mathrm{~kg}$ ) was again subjected to thorough physical mixing. The alkali-insoluble (humin) residues from the extraction were also recovered and are retained for future reference.

Cellulose. A large sample of bog oak representing a 20-ring growth span of dendro-calibrated age was provided by the University of Belfast archive (see Scott et al, 1989). The wood was chopped into small pieces and subjected to repeated digestion in $2 \mathrm{M}$ potassium hydroxide, washing, acidification and bleaching in sodium chlorite/hydrochloric acid solution. The fibrous extract was washed free of chlorite with distilled water, oven dried and thoroughly mixed by tumbling.

\section{Stage 3 Samples}

This final suite of samples was selected as representative of the raw materials used in routine dating. It was also considered beneficial to the assessment of the relative contribution of counting, chemical conversion and pretreatment in defining the true level of analytical confidence that these samples be compositionally similar to those of the previous stages and/ or represent wood of dendro-calibrated age. As in stages 1 and 2 , an element of duplication was built into the coded sample aliquots issued from the following:

Wood - from four growth sections, each of absolutely known age (to be revealed to participants at the completion of this stage) provided by the University of Belfast. For precise intercomparison, recipients were asked to provide an age value for the complete growth span represented in each sample.

Shell - bivalve mollusks (Anadara antiquata) from a midden near the surface of wind-blown sand facies in beach fore-dune, Moa Island, Torreo Strait, North Queensland, Australia. The bulk sample was excavated from $25-35 \mathrm{~cm}$ depth in $1 \mathrm{~m}^{2}$ (site code: MOA MID/81/02) August 1981 by D R Harris, University of London. As an aid to determining an appropriate pretreatment, recipients were advised that modern specimens of this species have an aragonite structure. 
Peat - from the original bulk collection used to prepare the stage 2 "humic extract". The aliquots issued are least representative of typical user submissions due to the need to produce a homogeneous bulk sample. However, this material should be advantageous in highlighting any differences in the final age pattern that arise from the pretreatment procedures preferred by individual laboratories.

\section{SUPPLEMENTARY SAMPLES}

A feature of the samples prepared for the formal intercalibration program is the relatively young age range covered, $i e,<2$ half-lives in all instances. This reflects the preference of participants and also the difficulties encountered in obtaining adequate amounts of older material of a suitable composition.

The NERC Laboratory has recently prepared two bulk samples which can be made available to laboratories that wish to intercalibrate at the more extreme range of the ${ }^{14} \mathrm{C}$ time scale, 1) marine turbidite comprising $>60 \%$ coccolith calcite with an age of ca 18,000 yr BP, and 2) well-preserved wood from a deposit dated at $>40,000 \mathrm{yr}$ BP.

\section{ACKNOWLEDGMENTS}

On behalf of all participants in the study, we must thank D R Harris, University of London, D Sutherland, Placer Analyses, Edinburgh, and M Baillie and J Pilcher, University of Belfast, for their essential contribution to the identification and supply of bulk sample materials; technical staff at the SURRC, J Hannah, P Naysmith and K McKay, who assisted in the preparation, pretreatment and packaging of samples; finally, but by no means least, the Science and Engineering Research Council for the financial support without which the International Collaborative Study would have been possible.

\section{REFERENCES}

Clark, R M, 1975, A calibration curve for radiocarbon dates: Antiquity, v 69, p 251-266.

Godwin, H, 1962, Half-life of radiocarbon: Nature, v 195, p 984.

International Study Group (ISG), 1982, An inter-laboratory comparison of radiocarbon measurements in tree-rings: Nature, v 298, p 619-623. Groningen, PACT 8, p 123-133.

Mook, W G, 1985, Recommendations/resolutions adopted by the Twelfth International Radiocarbon Conference, in Stuiver, $\mathrm{M}$ and $\mathrm{Kra}, \mathrm{R} \mathrm{S}$, eds, Internatl ${ }^{14} \mathrm{C}$ conf, 12 th, Proc: Radiocarbon, v 28, no. 2A, p 797 .

Otlet, R L, Walker, A J, Hewson, A D and Burleigh, R, $1980,{ }^{14} \mathrm{C}$ interlaboratory comparison in the UK: Experiment design, preparation and preliminary results, in Stuiver, $M$ and Kra, R S, eds, Internatl ${ }^{14} \mathrm{C}$ conf, 10th, Proc: Radiocarbon, v 22, no. 3, p 936-947.

Pardi, R and Marcus, L, 1977, Non-counting errors in ${ }^{14} \mathrm{C}$ dating: Annals N Y Acad Sci, v 288, p 174-180.

Scott, E M, Aitchison, T C, Harkness, D D, Baxter, M S and Cook, G T, 1989, An interim progress report on Stages 1 and 2 of the International Collaborative program: Radiocarbon, this issue. 
Scott, E M, Baxter, M S, Aitchison, T C, Harkness, D D and Cook, G T, 1986, Announcement of a new collaborative study for intercalibration of ${ }^{14} \mathrm{C}$ dating laboratories: Radiocarbon, v 28, no. 1, p 167-169.

Stuiver, M, 1983, International agreements and the use of the new oxalic acid standard, in Stuiver, $\mathrm{M}$ and $\mathrm{Kra}, \mathrm{R} \mathrm{S}$, eds, Internatl ${ }^{14} \mathrm{C}$ conf, 11th, Proc: Radiocarbon, v 25, no. 2, p 793-795.

Stuiver, M and Polach, H A, 1977, Discussion: Reporting of ${ }^{14} \mathrm{C}$ data: Radiocarbon, v 19, no. 3, p 355-363.

Taylor, C B, 1978, Interlaboratory comparison of low-level tritium measurements in water: Internatl Jour Applied Radiation Isotopes, v 29, p 39-48. 